\title{
A organização partidária brasileira à luz da Constituição de 1988
}

Brazilian party organization in light of the 1988 Constitution

\section{Amandino Teixeira Nunes Junior ${ }^{1}$}

\section{RESUMO}

Este artigo intenta examinar a organização partidária brasileira à luz da Constituição de 1988, com foco nas disposições normativas relativas à estrutura e ao funcionamento dos partidos políticos. Discute a origem e a evolução histórica dos partidos políticos, seu conceito, suas funções e sua tipologia de acordo com Maurice Duverger. Discute, também, o pluripartidarismo, a liberdade e a autonomia partidárias, a disciplina e a fidelidade partidárias, e o caráter nacional dos partidos políticos como princípios norteadores da organização partidária.

Palavras-chave: Organização partidária. Partido político. Pluripartidarismo. Fidelidade partidária.

\section{ABSTRACT}

This paper attempts to examine Brazilian party organization in light of the 1988 Constitution, focusing on rules and regulations concerning the structure and functioning of political parties. It discusses the origin and historical evolution of political parties, their concept, their functions and their typology according to Maurice Duverger. It also discusses the multiparty system, party freedom and autonomy, party discipline and fidelity, and the national character of political parties as guiding principles of party organization.

Keywords: Party organization. Political party. Multiparty system. Party fidelity.

\footnotetext{
1 Graduado em Direito pela PUC Minas, mestre em Direito pela UFMG, doutor em Direito pela UFPE, doutor em Ciência Política pela UnB, pós-doutor em Democracia e Direitos Humanos pela Universidade de Coimbra (Portugal), professor universitário e consultor legislativo aposentado da Câmara dos Deputados. Orcid: https://orcid.org/0000-0003-4100-0026.
} 


\section{INTRODUÇÃO}

O presente artigo pretende examinar a organização partidária brasileira, com base na Constituição de 1988. Inicialmente, são abordadas a origem e a evolução histórica dos partidos políticos no Brasil e em outros países.

Em seguida, são discutidos o conceito, as funções e a tipologia dos partidos políticos, segundo Maurice Duverger. Adiante, são estudados os partidos à luz da Constituição de 1988, com foco na sua natureza jurídica e na sua importância para o sistema democrático, bem como nos princípios do pluripartidarismo, da liberdade e da autonomia partidárias, e da disciplina e da fidelidade partidárias.

Finalmente, à guisa de conclusão, é exposta a opinião do autor sobre a temática aqui estudada.

\section{ORIGEM E EVOLUÇÃO HISTÓRICA DOS PARTIDOS POLÍTICOS}

Segundo Duverger (1996, p. 9), "en general, el desarrollo de los partidos politicos parece ligado al de la democracía, es decir, a la extensión del sufragio popular y de las prerrogativas parlamentariais". O surgimento dos partidos políticos, portanto, está intimamente ligado à necessidade da participação dos setores da sociedade civil na formação das decisões políticas.

Assinala Motta (2008, p. 14) que, já no século 18, começaram a ocorrer movimentos de contestação aos excessos praticados pelo poder monárquico-absolutista. Também teve desenvolvimento um corpo de ideias liberais, que defendiam a liberdade individual frente ao Estado. No reinado de Carlos II, formaram-se os partidos Whig e Tory, cuja evolução veio a dar no Partido Liberal e no Partido Conservador. Mais tarde é que se formou o Partido Trabalhista, de origem sindicalista. 
Na França, os partidos políticos começaram a se formar no decorrer da nova ordem liberal implantada pela Revolução de 1789, inicialmente, porém, em forma de associações civis e clubes. A mais importante dessas agremiações foi a Sociedade dos Amigos da Constituição, posteriormente transformada no Clube dos Jacobinos, que reunia deputados e líderes monarquistas que aderiram ao movimento republicano após a execução de Luís XVI. Com Napoleão Bonaparte, eclipsaram-se os partidos nascentes, reaparecendo, em 1814, sob a égide da Carta Constitucional de Luís XVIII. Reuniram-se, assim, as várias correntes dispersas na formação dos dois poderosos partidos: o Partido Conservador e o Partido Liberal.

Na Alemanha, as primeiras formações partidárias datam da Revolução de 1848, também sob as denominações Conservador e Liberal, nos moldes clássicos da política inglesa.

Nos Estados Unidos, o primeiro partido se esboçou logo no seio da Convenção da Filadélfia de 1787, quando se estruturaram as bases da União das treze colônias libertadas do jugo inglês, sendo organizado por Thomas Jefferson, sob a denominação de Partido Democrático. Mais tarde, em 1854, veio a surgir o Partido Republicano.

No Brasil, o ano de 1831 é indicado como o do surgimento do primeiro partido político - denominado Partido Liberal -, seguido pelo Partido Conservador, em 1838. Essas duas agremiações partidárias revezaram-se no poder durante o Segundo Império, quando, também, os republicanos começaram a se aglutinar para formar, em 1870, o respectivo partido. Na verdade, o movimento republicano fragmentou-se nos partidos estaduais na Primeira República, quais sejam, PRP, PRM, PRRG, PRBA etc.

Assinala Silva (2012, p. 396) que, depois de finda a Primeira República, com a Revolução de 1930,

surgem novas formações partidárias ainda de caráter regional: Partido Democrático em São Paulo, Partido Nacionalista em Minas Gerais, Partido Libertador no Rio Grande do Sul, além 
do Clube Três de outubro e a Aliança Renovadora Nacional. Mas foi no período de 1946 a 1965 que floresceu um sistema partidário com alguma institucionalização efetiva com base em três grandes partidos de âmbito nacional - o Partido Social Democrático (PSD), a União Democrática Nacional (UDN) e o Partido Trabalhista Brasileiro (PTB) - e um conjunto de pequenos partidos de expressão basicamente regional (PSP, PL, PDC, PRT, PTN, MTR), embora o PDC estivesse mais desenvolvido, além do Partido Comunista, na clandestinidade após 1948.

Em 1965, com a edição do Ato Institucional n ${ }^{0} 2$ (AI-2), são extintos os partidos existentes, dando margem ao surgimento do bipartidarismo representado pela Aliança Renovadora Nacional (ARENA), que reunia os políticos pró-regime militar, e pelo Movimento Democrático Brasileiro (PMDB), que reunia os políticos de oposição ao regime militar. Esses partidos foram extintos em 1979.

Com a promulgação da Constituição de 1988 e a redemocratização do país, reimplantou-se, no Brasil, o pluripartidarismo com o funcionamento de um grande número de agremiações partidárias de diferentes matizes. Atualmente, há trinta e três partidos políticos registrados no Tribunal Superior Eleitoral.

Assim, podemos dizer que o sistema partidário brasileiro tende a ser caracterizado, nos dias atuais, como um sistema composto por um grande número de partidos políticos, porém sem enraizamento social e com alto índice de fragmentação partidária. Os partidos são pouco coesos, indisciplinados e organizados, na maioria das vezes, para atender a interesses pessoais de líderes ou de grupos hegemônicos. O grande número de partidos existentes hoje, no Brasil, certamente acaba por acarretar alguns problemas; afinal, boa parte das legendas nanicas, atomizadas e de aluguel apenas contribui para inflacionar o número de candidatos a cargos eletivos da vida pública. O eleitor, atônito e ávido pela melhor escolha, vê-se, por fim, atormentado pela ampla oferta no mercado eleitoral. 


\section{CONCEITO, FUNÇÕES E TIPOLOGIA DOS PARTIDOS POLÍTICOS}

O conceito de partidos deve incluir três critérios fundamentais: a lógica de projeto, a lógica de organização e a lógica de mobilização. Nesse sentido, Seiler (2000, p. 25) afirma que partidos políticos são "organizações visando a mobilizar indivíduos numa ação coletiva conduzida contra outros, paralelamente mobilizados, a fim de alcançar sozinhos ou em coalizão, o exercício das funções de governo".

Para Silva (2012, p. 396), os partidos políticos são "uma forma de agremiação de um grupo social que se propõe organizar, coordenar e instrumentar a vontade popular com o fim de assumir o poder para realizar seu programa de governo".

Segundo Gomes (2018, p. 128),

compreende-se por partido político a entidade formada pela livre associação de pessoas, como organização estável, cujas finalidades são alcançar e/ou manter de maneira legítima o poder político-estatal e assegurar, no interesse do regime democrático de direito, a autenticidade do sistema representativo, o regular funcionamento do governo e das instituições políticas, bem como a implementação dos direitos humanos fundamentais.

Em uma definição nossa, podemos dizer que os partidos políticos são instâncias associativas permanentes e estáveis, dotadas de ideologia e programa próprios, destinadas à arregimentação coletiva, tendo em vista a conquista do poder, seja pela ocupação de cargos, seja pela capacidade de influenciar nas decisões políticas.

Observa Aras (2006, p. 243) que

os partidos políticos, ao aglutinarem pessoas e grupos de diferentes matizes sociais, tornam-se depositários da confiança de seus filiados e adeptos na solução dos problemas pessoais 
(emprego, educação, lazer), da comunidade (saneamento básico, saúde e segurança públicas) e de realização de suas expectativas (justiça, paz, bem comum).

Assim, os partidos políticos têm como funções fundamentais organizar a vontade popular e exprimi-la na busca do poder, com vistas à aplicação de seus programas de governo.

Do ponto de vista da tipologia, os partidos políticos, segundo Duverger (1996), são de dois tipos: os partidos de quadros e os partidos de massa. Para o autor, as diferenças entre esses partidos residem na sua origem.

Os partidos de quadros são aqueles criados dentro do poder político. São, em geral, instituídos por grupos parlamentares que residem no interior dos órgãos legislativos. Historicamente, são anteriores ao sufrágio universal.

Os partidos de massa são aqueles criados em decorrência de movimentos sociais, grupos associativos, ligas, sociedades secretas, organizações e sindicatos que atuavam na sociedade, mas que não tinham representação política.

Para Duverger (1996), os partidos de quadros seriam arcaicos e destinados a sucumbir frente aos partidos de massa. Estes representariam o futuro dos partidos políticos. Entretanto, o curso dos fatos parece não ter acompanhado esse cenário.

Com efeito, de um lado, os partidos de massa não só continuaram a existir como têm demonstrado sua força sem sinais de redução; de outro lado, os partidos de massa encontram desafios cada vez maiores em face da diversidade ideológica dos movimentos sociais, mormente os de índole sindical. Na verdade, a redução do poder dos sindicatos nas sociedades atuais tem levado a um enfraquecimento da capacidade plebiscitária dos partidos de massa.

Por fim, observou-se, na dicotomia duvergiana, nos partidos de quadro/partidos de massa a existência de lacunas. Havia partidos políticos 
que organizavam e recrutavam o apoio de militantes, ainda que não fossem partidos de massa. Esses militantes desempenhavam um papel coadjuvante, pois cabia ao eleitorado o papel principal.

Surgiram, assim, os partidos de eleitores, distintos dos partidos de massa, pois, mesmo que apresentassem um número maior de militantes, não seriam orientados para seus militantes, como fazem os partidos de massa. Podemos dizer, também, que os partidos de eleitores se diferenciam dos partidos de massa quando recusam o dogmatismo ideológico, tornando seu discurso o mais amplo possível para propiciar a arregimentação do maior número de partidários.

Devemos, ainda, destacar as diferenças entre os partidos de eleitores e os partidos de quadros. A primeira diferença reside na aceitação completa e irrestrita da democracia de massas. Mesmo que, como todos os partidos, venham a se transformar em uma oligarquia mais ou menos aberta, os partidos de eleitores não são elitistas, na sua essência. Ao revés, buscam ser partidos populares. Nesse sentido, não possuem aversão às manifestações populares e aos outros tipos de ação política provenientes das massas.

\section{PARTIDOS POLÍTICOS À LUZ DA CONSTITUIÇÃO DE 1988}

A Constituição de 1988, no seu art. 17, dispõe sobre os partidos políticos como instrumentos necessários e importantes para a preservação do Estado Democrático de Direito, afirmando a liberdade de criação, fusão, incorporação e extinção dos partidos políticos e conferindo-lhes a função de assegurar, resguardados a soberania nacional, o regime democrático e o pluripartidarismo, a autenticidade do sistema representativo e de defender os direitos fundamentais da pessoa humana, e observados os preceitos de caráter nacional, a proibição de recebimento de recursos financeiros de entidade ou de governos estrangeiros ou de subordinação a estes, a prestação de contas à Justiça Eleitoral e o funcionamento parlamentar de acordo com a lei. 
$\mathrm{O}$ art. $17, \S 1^{\circ}$, do texto constitucional vigente assegura aos partidos políticos autonomia para definir sua estrutura interna, sua organização e seu funcionamento, bem como para adotar os critérios de escolha e do regime de suas coligações eleitorais sem obrigatoriedade de vinculação entre candidatos em âmbito nacional, estadual, distrital e municipal, devendo seus estatutos estabelecer normas sobre fidelidade e disciplina partidárias, sendo vedada a utilização pelos partidos políticos de organização paramilitar $^{2}$.

No mesmo sentido, os arts. $2^{\circ}$ e $3^{\circ}$ da Lei $n^{\circ} 9.096 / 1995$ assim dispõem:

Art. $2^{\circ}$ É livre a criação, fusão, incorporação e extinção de partidos políticos, cujos programas respeitem a soberania nacional, o regime democrático, o pluripartidarismo e os direitos fundamentais da pessoa humana.

Art. $3^{\circ}$ É assegurada, ao partido político, autonomia para definir sua estrutura interna, organização e funcionamento (BRASIL, 2020).

Observe-se que a autonomia partidária, deferida constitucionalmente, imuniza o partido político da interferência do legislador ordinário, mas não o imuniza totalmente contra a atuação normativa do Legislativo, desde que compatível com os parâmetros estabelecidos pela Constituição de 1988.

Assim, o partido político, na tipificação das condutas consideradas atos de infidelidade partidária, deve respeitar os preceitos constitucionais (em especial, os direitos fundamentais, como a liberdade de expressão e de consciência) e legais (particularmente, a Lei no 9.096/1995 - Lei dos Partidos Políticos) para a imposição de sanções.

Com efeito, como o mandato, no Brasil, é representativo, não imperativo, o instituto deve ser aplicado com parcimônia, de modo a impedir a formação de uma ditadura partidária ou intrapartidária com o domínio de monopólios ou oligopólios políticos.

2 Saliente-se que, em face do princípio da autonomia partidária, torna-se incompetente a Justiça Eleitoral para julgar matéria interna corporis dos partidos políticos (Cf. TSE - Pleno - Consulta $\mathrm{n}^{\circ}$ 1251/DF - Rel. min. Carlos Ayres Britto). 
Nesse sentido, aduz Clève (1998, p. 31) que

\begin{abstract}
Mesmo que necessário o instituto para manutenção da coesão partidária, ele não pode ser utilizado ao ponto de: (i) ofender a natureza da representação; (ii) substanciar mecanismo de violação aos direitos fundamentais dos mandatários; (iii) implicar desvio de finalidade (a pretexto de manter a coesão partidária faculta-se o controle das minorias oligárquicas sobre os mandatários); (iv) permitir a cassação dos direitos políticos dos filiados eventualmente expulsos. Ou seja, o território da fidelidade partidária não é ilimitado, sendo certo que suas fronteiras derivam também da incidência da Constituição Federal. Apenas uma interpretação sistemática da Constituição é capaz de ilustrar os verdadeiros contornos do instituto. Qualquer interpretação isolada do texto do art. $17, \S 1^{\circ}$, da Constituição, portanto, ensejará a emergência de um sentido falseado do texto constitucional e, nomeadamente, do regime de fidelidade.
\end{abstract}

Relativamente à natureza jurídica dos partidos políticos, a Constituição de 1988 os define como pessoa jurídica de direito privado, nos termos do art. $17, \S 2^{\circ}$, segundo o qual os partidos políticos, depois de adquirirem personalidade jurídica, na forma da lei civil, registrarão seus estatutos no Tribunal Superior Eleitoral, após o que terão direito aos recursos do fundo partidário e ao acesso gratuito ao rádio e à televisão.

Por sua vez, o art. $1^{\circ}$ da Lei $n^{\circ} 9.096 / 1995$, que "dispõe sobre partidos políticos, regulamenta os arts. 17 e $14 \$ 3^{\circ}$, inciso V, da Constituição Federal", diz que "o partido político, pessoa jurídica de direito privado, destina-se a assegurar, no interesse do regime democrático, a autenticidade do sistema representativo e a defender os direitos fundamentais definidos na Constituição Federal".

Como se observa, os partidos políticos se apresentam, no ordenamento jurídico brasileiro, como pessoas jurídicas de direito privado e seus estatutos devem ser registrados no cartório competente do Registro Civil das Pessoas Jurídicas do local de sua sede (Lei n ${ }^{\circ}$ 9.096/1995, art. $8^{\circ}$ ). 
Adquirida a personalidade jurídica, na forma da lei civil, os estatutos partidários devem ser, de igual modo, registrados no Tribunal Superior Eleitoral. Esse fato confere aos partidos políticos a capacidade eleitoral necessária para participar das eleições e da propaganda eleitoral gratuita no rádio e na televisão, além de receber cotas do fundo partidário e defender seus símbolos.

Os partidos políticos constituem, assim, à luz da Constituição de 1988, um dos pilares do regime democrático e funcionam como instrumentos por meio dos quais se realiza a representação política. Em relação a esta, mencione-se o fato de que o sistema eleitoral brasileiro não admite candidaturas avulsas, tendo em vista que o art. $14, \S 3^{\circ}, \mathrm{V}$, da Constituição de 1988, exige a filiação partidária como uma das condições de elegibilidade. A par disso, a Lei $\mathrm{n}^{\circ}$ 13.488/2017 acrescentou à disciplina do registro de candidatura o $\$ 14$ ao art. 11 da Lei no 9.504, de 1997 (Lei das Eleições), com o seguinte teor:

Art. 11. [...]

§14. É vedado o registro de candidatura avulsa, ainda que o requerente tenha filiação partidária.

Como exemplo da importância atribuída pela Constituição de 1988 aos partidos políticos, mencione-se o comando do referido $\S 1^{\circ}$ do art. 17 , que confere aos respectivos estatutos a atribuição de estabelecer normas de fidelidade e disciplina partidárias - atribuição essa que não se traduz em mera faculdade, mas em efetivo dever. É dizer que os estatutos partidários terão de prever tais normas acarretando consequências no caso de seu descumprimento.

Observa Silva (2012, p. 407) que

a disciplina não há de entender-se como obediência cega aos ditames dos órgãos partidários, mas respeito e acatamento do programa e objetivo dos partidos, às regras de seu estatuto, cumprimento de seus deveres e probidade no exercício de man- 
datos ou funções partidárias, e, num partido de estrutura interna democrática, por certo que a disciplina compreende a aceitação das decisões discutidas e tomadas pela maioria de seus filiados-militantes.

Nesse diapasão, convém mencionar a chamada cláusula de barreira que se traduz na limitação ou no impedimento da atuação parlamentar de partido político que não alcança determinado percentual de votos. É adotada pelas legislações de diversos países. No Brasil, essa exigência de votação mínima foi introduzida pela Emenda Constitucional no 97/2017, que deu nova redação ao art. $17, \S^{\circ}$, da Constituição de 1988 , nos seguintes termos:

\footnotetext{
Art. $17[\ldots]$

$\S 3^{\circ}$ Somente terão direito a recursos do fundo partidário e acesso gratuito ao rádio e à televisão, na forma da lei, os partidos políticos que alternativamente:

I - Obtiverem, nas eleições para a Câmara dos Deputados, no mínimo, 3\% (três por cento) dos votos válidos, distribuídos em pelo menos um terço das unidades da Federação, com um mínimo de $2 \%$ (dois por cento) dos votos válidos em cada uma delas;

II - Tiverem elegido pelo menos quinze Deputados Federais distribuídos em pelo menos um terço das unidades da Federação". (BRASIL, 1988)
}

\section{DISCIPLINA E FIDELIDADE PARTIDÁRIAS COMO PRINCÍPIOS DA ORGANIZAÇÃO PARTIDÁRIA}

A disciplina e a fidelidade partidárias são erigidas pela Constituição de 1988 à condição de princípios da organização e do funcionamento dos partidos políticos, devendo constar dos estatutos partidários. Não são, repita-se, meras faculdades estatutárias. $\mathrm{Na}$ verdade, os estatutos terão que os prever, bem como estabelecer sanções para os atos de indisciplina e de infidelidade partidárias. 
Assinala Aras (2006, p. 244-245) que

[a] fidelidade e a disciplina partidárias são figuras que integram o elenco de direitos e garantias fundamentais, de aplicação imediata, cabendo aos partidos políticos estabelecer, nos seus estatutos, as regras descritivas das infrações e respectivas penalidades, dentre as quais, se pode incluir a perda do mandato, sem confrontar nenhuma outra norma da mesma índole constitucional.

Com efeito, a fidelidade partidária figura no $\S 1^{\circ}$ do art. 17 da Constituição de 1988, que assim dispõe:

\begin{abstract}
Art. 17. [...]
$\S 1^{\circ}$ É assegurada aos partidos políticos autonomia para definir sua estrutura interna, organização e funcionamento e para adotar os critérios e o regime de suas coligações eleitorais, sem obrigatoriedade de vinculação entre as candidaturas em âmbito nacional, estadual, distrital ou municipal, devendo seus estatutos estabelecer normas de disciplina e fidelidade partidária.
\end{abstract} (BRASIL, 1988)

Como se observa, a Constituição de 1988 remete à regulamentação do instituto para os estatutos partidários, com a exclusão da possibilidade de perda do mandato em razão da infidelidade partidária. É dizer: o texto constitucional vigente não obriga a permanência do agente político (do Poder Legislativo ou do Poder Executivo) no partido sob cuja legenda fora eleito, nem prevê qualquer penalidade para a troca de partidos. Ao revés, até proíbe a perda do mandato por infidelidade partidária, quando, no seu art. 15, declara vedada a cassação de direitos políticos, só admitidas a perda e a suspensão deles nos casos expressamente indicados no mesmo artigo.

Ademais, a Constituição de 1988, ao dispor sobre as condições de elegibilidade, determina, no seu art. $14, \S 3^{\circ}$, V, a filiação partidária como uma das exigências para o cidadão postular a candidatura a qualquer cargo eletivo. 
Condição de elegibilidade $\mathrm{e}$, portanto, pressuposto para a candidatura e a aquisição do mandato eletivo, a filiação partidária, que a Constituição de 1988 exige (art. 14, $\S 3^{\circ}, \mathrm{V}$ ), é fator determinante da fidelidade partidária no sentido de exigir dos filiados a observância dos princípios doutrinários e das diretrizes programáticas constantes dos estatutos partidários. É o que determina, no plano infraconstitucional, a Lei no 4.737 , de 1965, que instituiu o Código Eleitoral, e a Lei no 9.096 , de 1995, que dispõe sobre os partidos políticos e regulamenta dispositivos da Constituição vigente.

Assim, a Lei no 4.737, de 1965 (Código Eleitoral), estabelece, no seu art. 87, caput, que somente podem concorrer às eleições os candidatos registrados por partidos.

Por sua vez, a Lei no 9.096, de 1995 (Lei dos Partidos Políticos), determina, no seu art. 15, V, que o estatuto do partido deve conter, entre outras, normas sobre: "V - fidelidade e disciplina partidária, processo para apuração das infrações e aplicação das penalidades, assegurado amplo direito de defesa".

$\mathrm{O}$ capítulo $\mathrm{V}$ do mencionado diploma legal cuida da fidelidade e da disciplina partidárias, no qual se incluem os arts. 23, 24 e 25, que estabelecem:

Art. 23. A responsabilidade por violação dos deveres partidários deve ser apurada e punida pelo competente órgão, na conformidade do que disponha o estatuto de cada partido.

$\S 1^{\circ}$ Filiado algum pode sofrer medida disciplinar ou punição por conduta que não esteja tipificada no estatuto do partido político.

$\S 2^{\circ}$ Ao acusado é assegurado amplo direito de defesa.

Art. 24. Na Casa Legislativa, o integrante da bancada de partido deve subordinar sua ação parlamentar aos princípios doutrinários e programáticos e às diretrizes estabelecidas pelos órgãos de direção partidários, na forma do estatuto. (BRASIL, 1995). 
É a consagração, na legislação infraconstitucional, especificamente na Lei dos Partidos Políticos, do instituto da fidelidade partidária.

Quanto às penalidades decorrentes da infidelidade partidária, os arts. 25 e 26 do mencionado diploma legal estabelecem que:

Art. 25. O estatuto do partido poderá estabelecer, além das medidas disciplinares básicas de caráter partidário, normas sobre penalidades, inclusive com desligamento temporário da bancada, suspensão do direito de voto nas reuniões internas ou perda de todas as prerrogativas, cargos e funções que exerça em decorrência da representação e da proporção partidária, na respectiva Casa Legislativa, ao parlamentar que se opuser, pela atitude ou pelo voto, às diretrizes legitimamente estabelecidas pelos órgãos partidários."

Art. 26. Perde automaticamente a função ou cargo que exerça, na respectiva Casa Legislativa, em virtude da proporção partidária, o parlamentar que deixar o partido sob cuja legenda tenha sido eleito. (BRASIL, 1995)

Note-se que, consoante o art. 25, acima transcrito, a pena máxima que o estatuto do partido pode estabelecer, no caso de infidelidade partidária, é a desfiliação e a expulsão do filiado.

$\mathrm{Na}$ verdade, os casos de perda de mandato estão expressamente previstos no art. 55 da Constituição de 1988, não podendo ser eles ampliados por norma infraconstitucional ou pelo estatuto partidário.

Nesse sentido, cabe apenas ao Poder Legislativo promover a mudança desse dispositivo constitucional para nele incluir a hipótese de perda do mandato por infidelidade partidária, e não a qualquer outro Poder, sob pena de inconstitucionalidade por usurpação de função.

Entretanto, a jurisprudência do Tribunal Superior Eleitoral e do Supremo Tribunal Federal entendeu que os mandatos pertencem aos partidos e às coligações, que, por conseguinte, podem preservá-los no caso de cancelamento da filiação partidária ou de mudança de legenda, sem justa causa, ou seja, podem requerer à Justiça Eleitoral a cassação do mandato parlamentar infiel. 
Esse entendimento adveio de uma decisão do Tribunal Superior Eleitoral, proferida no julgamento da Consulta $\mathrm{n}^{\circ}$ 1.398, em 27/03/2007, posteriormente ratificada pelo Supremo Tribunal Federal, segundo a qual, nos pleitos majoritários e proporcionais, a troca de partido, pelo eleito, sem justo motivo, poderá implicar a perda do mandato, já que este pertence ao partido e às coligações, e não ao político.

Em 2015, o Supremo Tribunal Federal alterou o entendimento até então fixado com relação às eleições majoritárias na apreciação da constitucionalidade da Resolução TSE n ${ }^{\circ}$ 22.610/2007. Assim, no julgamento da ADI $n^{\circ}$ 5.081-DF, realizado em 27 de maio de 2015, tendo como relator o ministro Luís Roberto Barroso, o Pretório Excelso decidiu que a perda do mandato em face da troca de legenda não mais se aplica ao sistema majoritário (adotado na eleição de presidente, governador, prefeito e senador) sob a alegação de que este tem lógica e dinâmica distintas do sistema proporcional (adotado na eleição de deputados federais, estaduais, distritais e de vereadores) e que, portanto, a hipótese afronta a soberania popular e as escolhas do eleitor.

$\mathrm{Na}$ reinterpretação do instituto da fidelidade partidária em face do julgamento da $\mathrm{ADI} \mathrm{n}^{\circ}$ 5.91-DF, entendeu o Excelso Pretório que a Resolução TSE $n^{\circ} 22.610 / 2007$, ao igualar os sistemas proporcional e majoritário em matéria de fidelidade partidária, vulnerou as características essenciais dos sistemas eleitorais e, principalmente, o núcleo do princípio democrático de que faz parte a soberania popular, porque desvirtua a vontade do eleitorado expressa nas eleições.

No ano de 2015, o Poder Legislativo resolveu enfrentar timidamente o tema da fidelidade partidária. A opção do legislador limitou-se a alterar uma hipótese de justa causa para mudança de partido, mantendo todo o regramento de natureza processual constante da Resolução TSE ${ }^{\circ}$ 22.610/2007. Assim, com a edição da Lei no 13.165/2015 (Minirreforma Eleitoral), a criação de novo partido deixou de configurar justa causa para 
troca de legenda. Além disso, o legislador criou a chamada "janela partidária" de 30 dias anteriores ao prazo mínimo de filiação - modificado para 6 meses - permitindo a livre migração de parlamentares, independentemente de os partidos serem novos ou antigos.

Por conta da Lei ${ }^{0} 13.165 / 2015$ (Minirreforma Eleitoral), a Rede Sustentabilidade ajuizou a ADI $n^{\circ} 5.398-D F$, na qual questiona a sua inconstitucionalidade por excluir a criação de nova legenda como hipótese de justa causa para a desfiliação sem perda do mandato por infidelidade partidária. Em julgamento publicado em 20/11/2018, o Excelso Pretório, por maioria e nos termos do voto do Relator, ministro Luís Roberto Barroso, referendou a concessão parcial da cautelar que determinou a devolução integral do prazo de 30 dias para filiações aos partidos registrados no Tribunal Superior Eleitoral até a data da entrada em vigor da Lei $n^{\circ}$ $13.165 / 2015$.

\section{CONCLUSÃO}

Em síntese conclusiva, podemos afirmar que, oficialmente, os partidos políticos já existem no Brasil há mais de cento e sessenta anos. Nenhum deles, contudo, dos bem mais de duzentos que surgiram nesse período, durou muito tempo. Não há partidos políticos centenários no país, como é comum, por exemplo, nos Estados Unidos, onde o Partido Democrata (desde 1790) e o Partido Republicano (desde 1837) alternam-se no poder. A razão dessa precariedade partidária e da falta de enraizamento histórico dos partidos políticos na vida institucional brasileira é a inconstância do nosso sistema político.

Devido a acontecimentos bruscos, como mudanças de regime, que golpearam a existência e a permanência das agremiações partidárias, os partidos políticos se viram, muitas vezes, forçados a recomeçar praticamente do zero uma nova trajetória a cada interrupção sofrida. Tais rupturas foram assinaladas pela implantação da República, em 1889, que 
sepultou os partidos monarquistas; pela Revolução de 1930, que desativou os partidos republicanos; pelo Estado Novo (1937-1945), que vedou a existência de partidos; e, por fim, pelo Regime Militar de 1964, que, artificialmente, instituiu o bicameralismo, confinando os partidos em uma verdadeira camisa de força.

Nas democracias contemporâneas, os partidos políticos tornaram-se peças fundamentais para o funcionamento do complexo mecanismo democrático. Em alguns casos, como é o brasileiro, os partidos políticos detêm o monopólio da representação popular, não havendo o exercício do poder estatal sem a intermediação partidária. A democracia é impensável sem a presença dos partidos políticos.

Os partidos políticos, no mundo atual, constituem, portanto, canais legítimos de organização e de transformação da vontade popular para exprimi-la na busca do poder, tendo em vista a realização de seu programa de governo.

A Constituição de 1988 define os partidos políticos como pessoas jurídicas de direito privado, cujos estatutos deverão ser registrados no Tribunal Superior Eleitoral. Consagra-os como instrumentos necessários e importantes para a preservação do Estado Democrático de Direito, afirmando a liberdade de criação, fusão, incorporação e extinção dos partidos políticos e conferindo-lhes a função de assegurar, resguardados a soberania nacional, o regime democrático e o pluripartidarismo, a autenticidade do sistema representativo e de defender os direitos fundamentais da pessoa humana, observados os preceitos de caráter nacional, a proibição de recebimento de recursos financeiros de entidade ou de governos estrangeiros ou de subordinação a estes, a prestação de contas à Justiça Eleitoral e o funcionamento parlamentar de acordo com a lei.

O texto constitucional vigente assegura, ainda, aos partidos políticos autonomia para definir sua estrutura interna, sua organização e seu funcionamento, bem como para adotar os critérios de escolha e do regime de suas coligações eleitorais sem obrigatoriedade de vinculação entre candidatos 
em âmbito nacional, estadual, distrital e municipal, devendo seus estatutos estabelecerem normas sobre fidelidade e disciplina partidárias, sendo vedada a utilização pelos partidos políticos de organização paramilitar.

Ao assegurar a autonomia dos partidos políticos, a Constituição de 1988 diminuiu consideravelmente o controle do Poder Público sobre as agremiações partidárias, visando, como assinalado por Temer (1994, p. 16):

\begin{abstract}
tentar criar (ou fortalecer) partidos políticos sólidos, comprometidos com determinada ideologia político-administrativa, uma vez que o partido há de ser o canal condutor a ser percorrido por certa parcela da opinião pública para chegar ao governo e aplicar o seu programa.
\end{abstract}

Portanto, à luz da Constituição de 1988, a organização dos partidos políticos deve atender aos princípios do pluripartidarismo, da liberdade e da autonomia partidárias, da disciplina e da fidelidade partidárias, além dos preceitos de caráter nacional e de prestação de contas à Justiça Eleitoral.

\title{
REFERÊNCIAS
}

ARAS, A. Fidelidade partidária: a perda do mandato parlamentar. Rio de Janeiro: Lumen Juris, 2006.

BRASIL. [Constituição (1988)]. Constituição da República Federativa do Brasil: texto constitucional promulgado em 5 de outubro de 1988, com as alterações adotadas pelas Emendas Constitucionais $\mathrm{n}^{\circ} 1 / 1992$ a 105/2019, pelo Decreto Legislativo no 186/2008 e pelas Emendas Constitucionais de Revisão no 1 a 6/94. Brasília: Câmara dos Deputados, Edições Técnicas, 2020.

BRASIL. Código eleitoral anotado e legislação complementar. Brasília: Tribunal Superior Eleitoral, Secretaria de Gestão da Informação, 2020. 
CLÈVE, C. M. Fidelidade partidária: estudo de caso. Curitiba: Juruá, 1998.

DUVERGER, M. Los partidos políticos. México: Fondo de Cultura Económica, 1996.

GOMES, J. J. Direito eleitoral. São Paulo: Atlas, 2018.

MOTTA, R. P. S. Introdução à história dos partidos políticos brasileiros. Belo Horizonte: Editora UFMG, 2008.

SEILER, D-L. Os partidos políticos. Brasília: Editora Universidade de Brasília; São Paulo: Imprensa Oficial do Estado, 2000.

SILVA. J. A. da. Curso de direito constitucional positivo. São Paulo: Malheiros, 2012.

TEMER, M. Constituição e política. São Paulo: Malheiros, 1994. 